\title{
Bilateral lid/brow elevation procedure for severe ptosis in Kearns-Sayre syndrome, a mitochondrial cytopathy
}

This article was published in the following Dove Press journal:

Clinical Ophthalmology

22 December 2014

Number of times this article has been viewed

\author{
Roberto Sebastiá ${ }^{1,2}$ \\ Ester Fallico ${ }^{3}$ \\ Matteo Fallico ${ }^{4}$ \\ Eduardo Fortuna ${ }^{5}$ \\ Sergio Lessa ${ }^{2,6}$ \\ Guilherme Herzog Neto' \\ 'Department of Ophthalmology, \\ Fluminense Federal University, \\ Niterói, ${ }^{2}$ Oculoplastic Surgery \\ Department, 38th Infirmary of the \\ Santa Casa de Misericordia do Rio \\ de Janeiro, Instituto Ivo Pitanguy, \\ Pontifícia Universidade Catolica do \\ Rio de Janeiro, Rio de Janeiro, Brazil; \\ ${ }^{3}$ Clinica Gretter, ${ }^{4}$ Facoltà di Medicina \\ e Chirurgia, Università degli Studi di \\ Catania, Catania, Italy; ${ }^{5}$ Hospital da \\ Plástica, ${ }^{6}$ Post-Graduate Program in \\ Physiopathology in Surgical Science, \\ State University of Rio de Janeiro, \\ Rio de Janeiro, Brazil
}

Background: The purpose of this work was to determine the effectiveness and possible complications encountered with bilateral fascia lata lid suspension used to correct blepharoptosis in patients with Kearns-Sayre syndrome.

Methods: This was a retrospective study of seven patients with Kearns-Sayre syndrome who had a minimum of 1 year of follow-up. A bilateral fascia lata sling was used to correct the ptosis. Preoperative and postoperative measurements of the vertical lid fissure width (VFW) and marginal reflex distance (MRD) were performed. The Student's $t$-test was used to analyze the results.

Results: The mean preoperative VFW and MRD measurements were $4 \pm 2.45 \mathrm{~mm}$ and $0.14 \pm 0.92 \mathrm{~mm}$, respectively. The mean postoperative VFW and MRD measurements were $7.71 \pm 1.85 \mathrm{~mm}$, and $2.86 \pm 1.69 \mathrm{~mm}$, respectively. All preoperative and postoperative values were considered to be statistically significant $(P<0.01)$. Adequate elevation of the lids was obtained in all patients, both functionally and aesthetically. All of the patients showed a mild symmetric postoperative inferior version lagophthalmos, and one patient developed corneal ulceration and scarring due to corneal exposure and a weak Bell's phenomenon.

Conclusion: The surgical technique described to correct the blepharoptosis found in patients with Kearns-Sayre syndrome was found to be efficient and relatively safe. The correction should be conservative to decrease the risk of postoperative corneal damage that occurred in one patient.

Keywords: Kearns-Sayre syndrome, blepharoptosis, fascia lata lid suspension, chronic progressive external ophthalmoplegia

\section{Introduction}

Kearns-Sayre syndrome (KSS) is a rare mitochondrial cytopathy. It was first described in a case report of two patients in 1958. ${ }^{1}$ The actual incidence of KSS is unknown, and the condition is said to be sporadic. ${ }^{2}$ Leveille et al described that in some cases it has been shown to be transferred through a mitochondrial autosomal dominant pattern. ${ }^{3}$ An autosomal recessive pattern is also described. ${ }^{4}$

The syndrome is characterized by a chronic progressive external ophthalmoplegia (CPEO), a progressive weakening of the eye muscles, and eye movements accompanied by ptosis (Figure 1). CPEO usually begins before the age of 20 years and is associated with retinal degeneration; other frequently associated abnormalities include cardiac disease, increased protein content in the cerebrospinal fluid, and ataxia. ${ }^{5}$ Sometimes these symptoms are associated with central nervous system dysfunction, such as skeletal muscle weakness (proximal more than distal), mental retardation, dementia,
Correspondence: Roberto Sebastiá Rua Gal Venâncio Flores, 230 apto 504, Rio de Janeiro 2244 I-090, Brazil Email robertosebastia@terra.com.br 

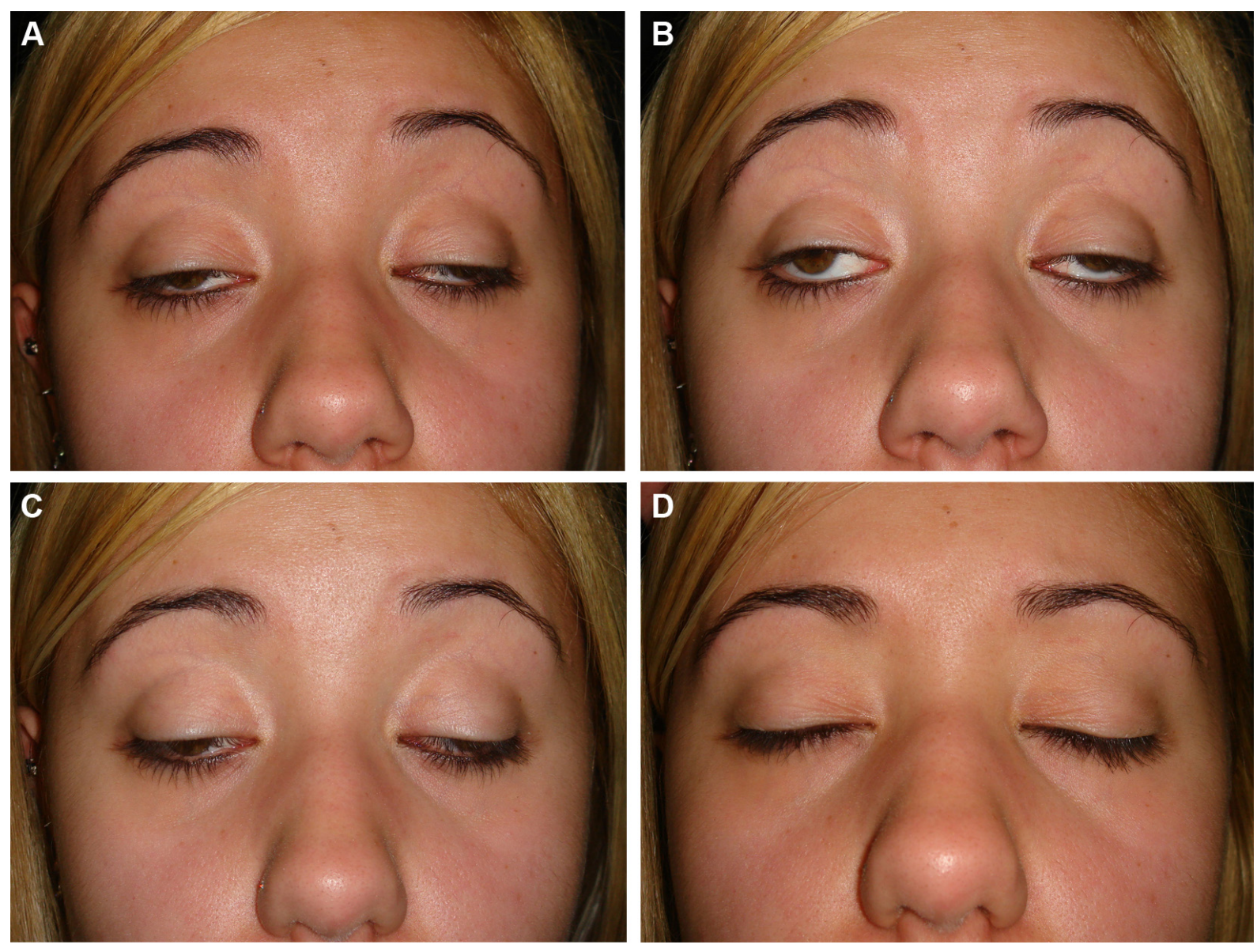

Figure I Severe eyelid ptosis and severe reduction of eye movements in a patient with Kearns-Sayre syndrome.

Notes: (A) Primary gaze position, (B) upper eye gaze, (C) downward eye gaze, and (D) eyelid occlusion.

dysarthria, dysphagia, dystonia, hearing loss, ataxia, bilateral facial weakness, and encephalopathy. ${ }^{6}$

The retinal degeneration found in KSS is a bilateral pigmentary retinopathy. ${ }^{7}$ It is diverse from the typical bone spicules found in retinitis pigmentosa. Severe dystrophic changes have been observed in the retina. ${ }^{8}$ Cardiac problems consist of conduction abnormalities, including heart block, bradycardia, palpitations, congestive heart failure, and cardiomyopathy. ${ }^{1,7,9}$

Diagnosis of KSS is based on the clinical features described above and supported by biochemical, radiological, histologic, and molecular genetic tests. Severe cardiac disturbances can be found with electrocardiographic and echocardiographic monitoring. Electroretinography is useful for evaluating retinal degeneration. Electromyographic studies may be normal or show soft muscle disease. A muscle biopsy may show the histologic features of a typical mitochondrial myopathy, such as the presence of "ragged red fibers". ${ }^{10}$

Treatment of KSS is symptomatic. The prognosis can vary according to severity of symptoms, although this syndrome is a progressive disorder. Administration of coenzyme $\mathrm{Q}^{10}$ has proven to be beneficial but of temporary benefit in individual cases of KSS. ${ }^{11}$ Future advances in the field of genetics may prove to be a more successful method for treating KSS patients.

The aim of this report is to evaluate effectiveness and complication rates of a bilateral lid suspension to the frontalis muscle using fascia lata autografts for correction of the eyelid ptosis found in patients with KSS. ${ }^{12}$

\section{Materials and methods}

This was a retrospective noncomparative interventional study of seven KSS patients who were operated on between January 1995 and December 2011 at the Antonio Pedro University Hospital, Federal Fluminense University, and the Oculoplastic Department, Ivo Pitanguy Institute. The Federal Fluminense University ethics research committee approved the study. The principles outlined in the Declaration of Helsinki were followed, and informed consent was obtained from all patients. 

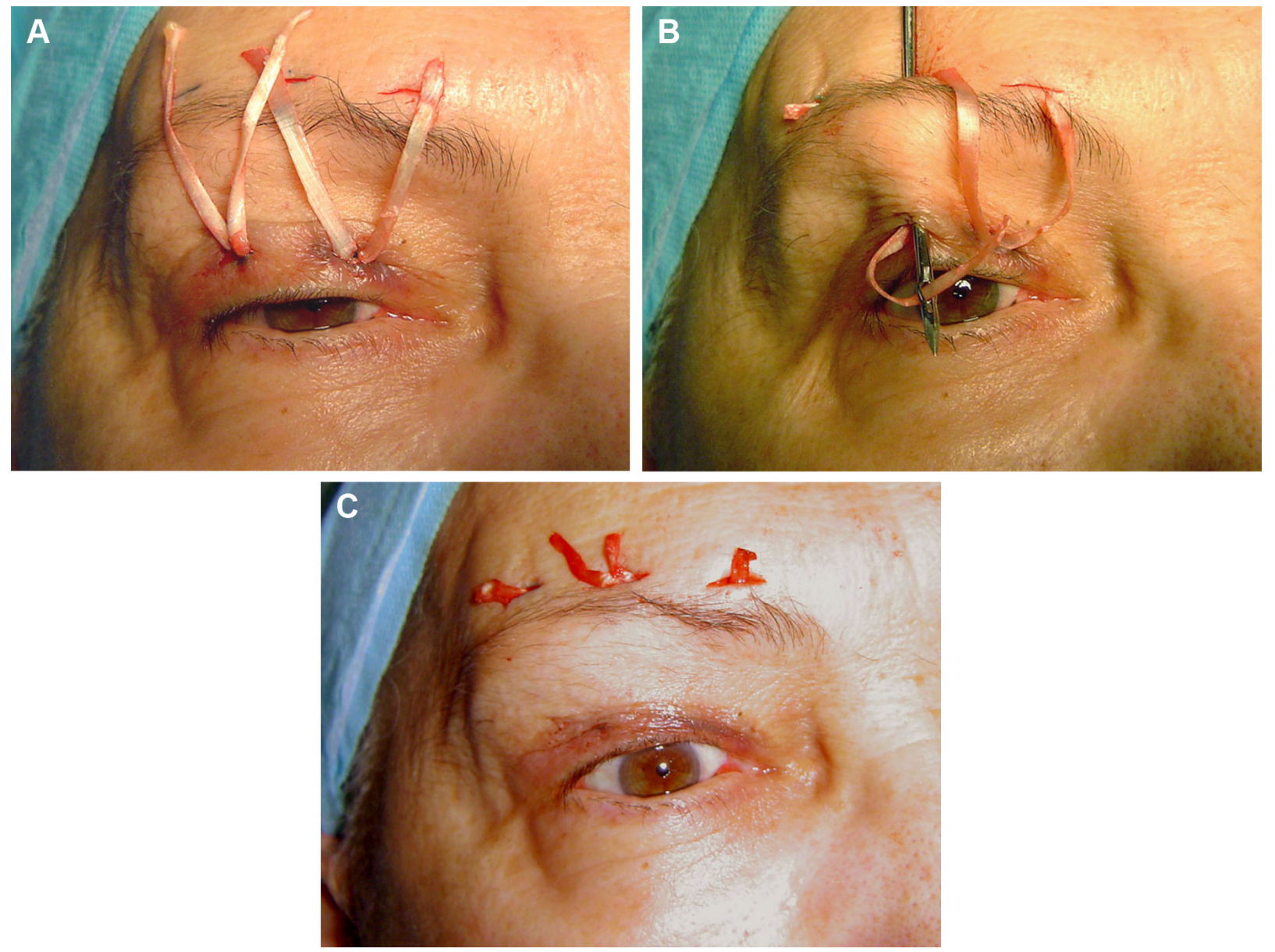

Figure 2 Eyelid-brow suspension with fascia lata.

Notes: (A) A strip of fascia $(60 \mathrm{~mm} \times 8 \mathrm{~mm})$ was divided into four thin strips of fascia measuring $60 \mathrm{~mm} \times 2 \mathrm{~mm}$. The strips were then sutured with 5 - 0 Nylon to the upper anterior part of each tarsus. (B) The fascia strips were passed beneath the orbicularis muscle. (C) They were sutured with 5-0 Nylon to the frontalis muscle above the brow in the manner of a "W". The central arm of the "W" determined the height of the lid margin and the other two arms of the W were placed to regulate lid contour.

Inclusion criteria were KSS patients with severe blepharoptosis that had not been previosly surgically treated. It was established at least 1-year postoperative follow-up. Patients with mild ptosis were not included in the study. Routine ophthalmologic examination was performed in all patients, and included a fundus examination, visual acuity, biomicroscopy, an intraocular pressure reading, and an eye motility test. All of our patients had a severe $(>4 \mathrm{~mm})$ ptosis with less than 5 $\mathrm{mm}$ superior lid elevator muscle function. Levator function was measured from downgaze to upgaze with the frontalis muscle held static. All patients had a positive history for $\mathrm{CPEO}$ and eye movements were extremely reduced. All eyes were orthophoric in primary gaze, and Bell's phenomenon was markedly reduced or absent in all patients.

The diagnosis was confirmed by fundus examination, fluorescein angiography, electrocardiography, echocardiography, and muscle biopsy with the Gömöri trichrome staining method. During funduscopic examination, multiple pigmentary changes were observed and fluorescein angiography showed atrophy of the retinal pigment epithelium. Electrocardiography showed a cardiac conduction disorder in all patients. Muscle biopsy showed histologic characteristics typical of a mitochondrial myopathy, such as the presence of "ragged red fibers", which were seen in all patients. Orbital and nasal images (routine X-ray and computed tomography scans) were performed to rule out other local pathology.

According to the inclusion criteria, seven KSS patients were selected for this study. They underwent a lid/brow suspension with fascia lata autografts. The same surgeon performed all the procedures. The preoperative and postoperative vertical lid fissure width (VFW) and marginal reflex distance (MRD) were used to evaluate the results, which were analyzed using the Student's $t$-test. Preoperative and 1-year postoperative photographic images were compared. 
Table I VFW and MRD values

\begin{tabular}{lllll}
\hline Patient & VFW $(\mathbf{m m})$ preoperative & VFW $(\mathbf{m m})$ postoperative & MRD $(\mathbf{m m})$ preoperative & MRD $(\mathbf{m m})$ postoperative \\
\hline 1 & 4 & 8 & 0 & 3 \\
2 & 4 & 8 & 0 & 3 \\
3 & 3 & 7 & 0 & 2 \\
4 & 4 & 7 & 0 & 3 \\
5 & 6 & 9 & 1 & 4 \\
6 & 4 & 8 & 0 & 3 \\
7 & 3 & 7 & 0 & 2 \\
\hline
\end{tabular}

Abbreviations: VFW, vertical lid fissure width; MRD, marginal reflex distance.

\section{Correction of lid ptosis}

Patients were placed under general anesthesia, with regional infiltration of lidocaine $1 \%$ with 1:100,000 adrenaline, and bupivacaine $0.5 \%$ and hyaluronidase $(10 \mathrm{IU} / \mathrm{mL})$ into the affected brow and superior eyelid.

A $60 \mathrm{~mm} \times 8 \mathrm{~mm}$ strip of fascia was obtained from the lateral portion of the thigh, and was then sutured with 3-0 Vicryl. This strip was divided into four thin strips of fascia measuring $60 \mathrm{~mm} \times 2 \mathrm{~mm}$, which were then sutured with 5-0 Nylon to the anterior part of each tarsus. The fascia strips were then passed posterior of the orbicularis muscle and sutured with 5-0 Nylon to the frontalis muscle in the form of a "W" (Figure 2). The central arm of the "W" was used to regulate the height of the lid margin, and the other two arms completed the lid contour.

\section{Statistical analysis}

The Student's $t$-test for continuous paired variables was used to compare the mean preoperative and postoperative VFW and MRD measurements. A $P<0.05$ level of probability was considered to be statistically significant. The analysis was performed using S-PLUS 8.0 software (Insightful Corporation, Seattle, WA, USA).

\section{Results}

Five of the seven patients were female. The age of the total sample ranged from 19 to 46 years, with an average age of 28 years. The follow-up period ranged from 14 months to 20 months, with an average of 17 months.

The preoperative VFW was $4 \mathrm{~mm}$ in four patients, $3 \mathrm{~mm}$ in two patients, and $6 \mathrm{~mm}$ in one patient. The preoperative MRD was $0 \mathrm{~mm}$ in six patients and $1 \mathrm{~mm}$ in one patient.
The mean preoperative VFW was $4 \mathrm{~mm}$ and the mean preoperative MRD was $0.14 \mathrm{~mm}$. The postoperative VFW was $7 \mathrm{~mm}$ in three patients, $8 \mathrm{~mm}$ in three patients, and $9 \mathrm{~mm}$ in one patient. The postoperative MRD was $2 \mathrm{~mm}$ in two patients, $3 \mathrm{~mm}$ in four patients, and $4 \mathrm{~mm}$ in one patient (Table 1). The mean postoperative VFW was $7.71 \mathrm{~mm}$ and the mean postoperative MRD was $2.86 \mathrm{~mm}$. All differences in preoperative and postoperative VFW and MRD (Table 2) were considered statistically significant $(P<0.01)$. Bell's phenomenon was reduced in all patients.

All patients showed a mild postoperative lagophthalmos in inferior version gazing. This is normally found in lid/brow suspension. One patient developed a more severe corneal exposure from the surgical procedure that resulted in a corneal ulcer and scarring (Figure 3), despite frequent instillation of eye lubricants. The ulcer was located inferiorly, so did not affect visual acuity. All patients achieved satisfactory elevation of the lids both functionally and aesthetically (Figures 4 and 5).

\section{Discussion}

$\mathrm{KSS}$ is a rare mitochondrial cytopathy. It was first described in 1958. ${ }^{1}$ The main ocular symptoms are a CPEO and superior eyelid ptosis that usually begins before the age of 20 years. Retinal degeneration is also found. KSS is frequently associated with cardiac disease, elevated protein content in cerebrospinal fluid, and ataxia. ${ }^{5} \mathrm{CPEO}$ consists of a slowly progressive weakening of the eye muscles and movements, resulting in immobile eyes fixed in the primary position and ptosis. ${ }^{7,9}$

The lid ptosis is bilateral and almost always severe and symmetrical. The levator muscle function test is also

Table 2 Mean VFW and MRD values

\begin{tabular}{llll}
\hline VFW $(\mathbf{m m})$ preoperative, $\mathrm{Cl}$ & VFW $(\mathbf{m m})$ postoperative, $\mathrm{Cl}$ & MRD $(\mathbf{m m})$ preoperative, $\mathbf{C l}$ & MRD (mm) postoperative, Cl \\
\hline $4.00 \pm 2.45$ & $7.71 \pm 1.85$ & $0.14 \pm 0.92$ & $2.86 \pm 1.69$
\end{tabular}

Notes: VFW, $P<0.01$; MRD, $P<0.01$.

Abbreviations: VFW, vertical lid fissure width; MRD, marginal reflex distance; $\mathrm{Cl}$, confidence interval. 


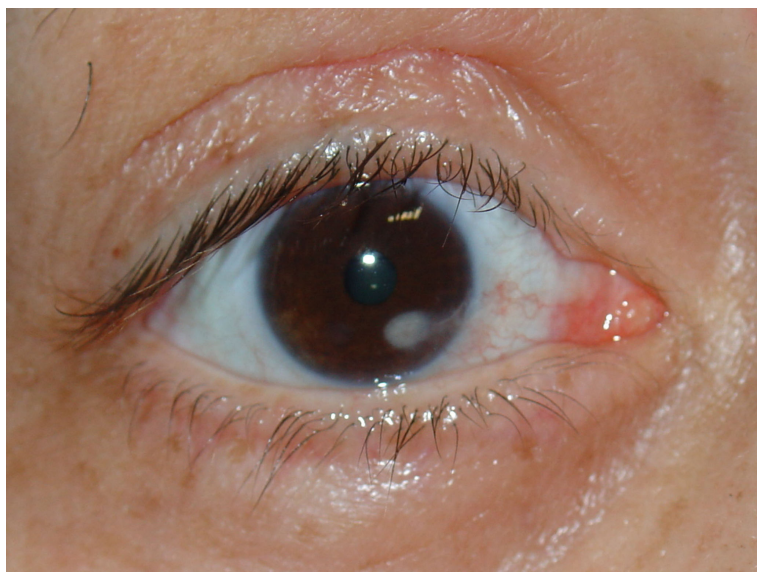

Figure 3 Corneal ulceration and leukoma caused by chronic corneal exposition.

almost always markedly reduced. The severe eyelid ptosis causes visual field restriction and deficient visual acuity, and patients tend to elevate their chins and lean their heads backwards so as to minimize these complaints. Brow suspension surgery should be limited because KSS patients have reduced orbicular muscle function as well as a reduced Bell's phenomenon which renders them susceptible to corneal exposure and ulceration.

In most diseases associated with ptosis, such as the blepharophimosis syndrome or isolated congenital ptosis, preservation of the extraocular muscles and eye movements makes the surgical outcome somewhat safer with respect to corneal exposure. Many authors base their choice of procedure for the treatment of ptosis based in levator muscle function; they shorten the muscle when its function is higher than $4 \mathrm{~mm}$ and perform a lid/brow suspension using a silicone or fascia lata when it is below $4 \mathrm{~mm} \cdot{ }^{12-15} \mathrm{In}$ patients with blepharophimosis syndrome, Nakajima et al always recommend a levator muscle reduction approach, and do not consider levator muscle function or severity of the ptosis. ${ }^{16}$

It is prudent to be cautious during correction of upper eyelid ptosis in patients with progressive external ophthalmoplegia because of the potential risk of postoperative corneal exposure and ulceration, which are enhanced by orbicularis oculi muscle paralysis and great reduction of Bell's phenomenon. ${ }^{17}$
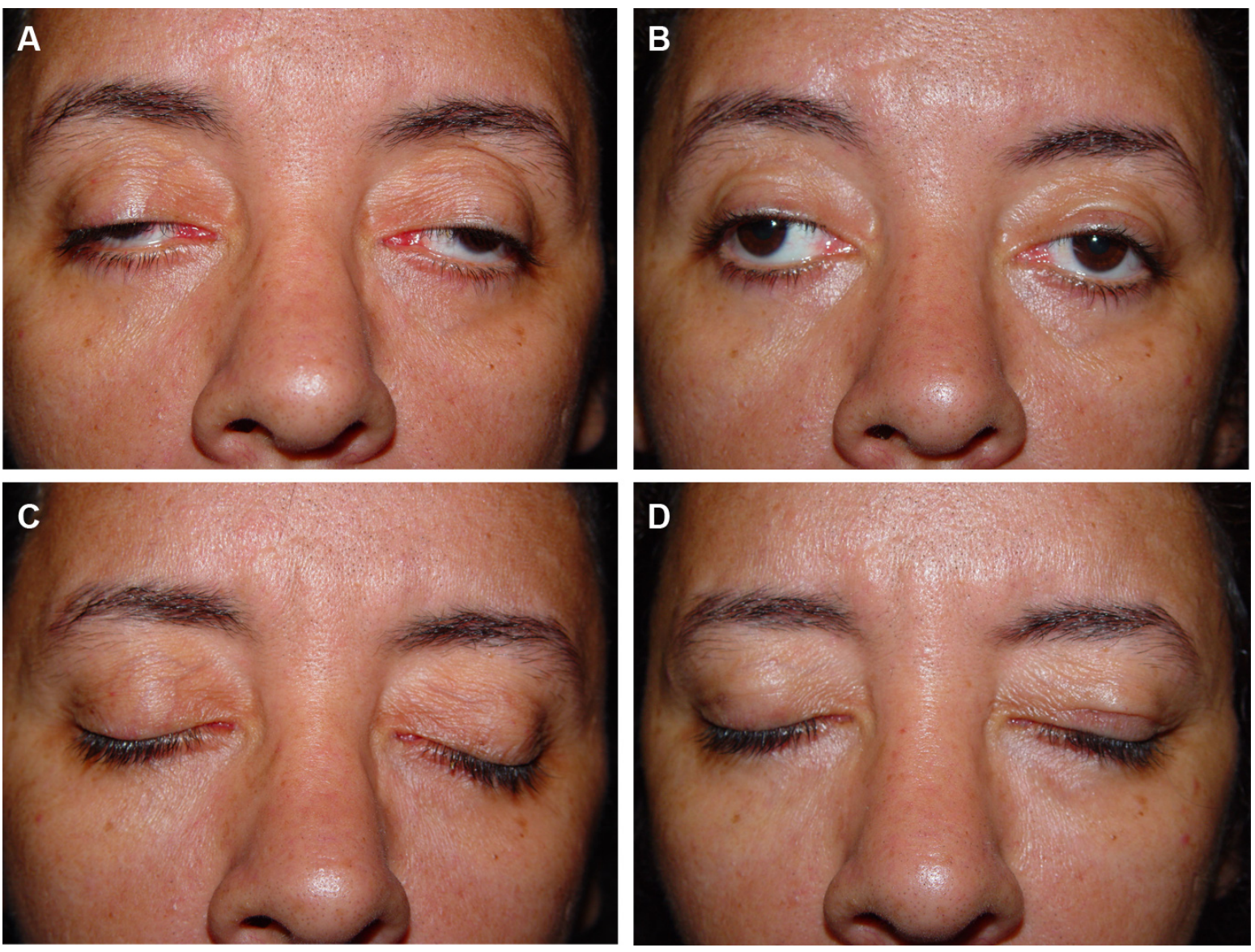

Figure 4 Preoperative and postoperative appearance of a 34-year-old female patient

Notes: (A) Preoperative and (B) 6-month postoperative photographs. (C) Preoperative eyelid closure and (D) postoperative. 

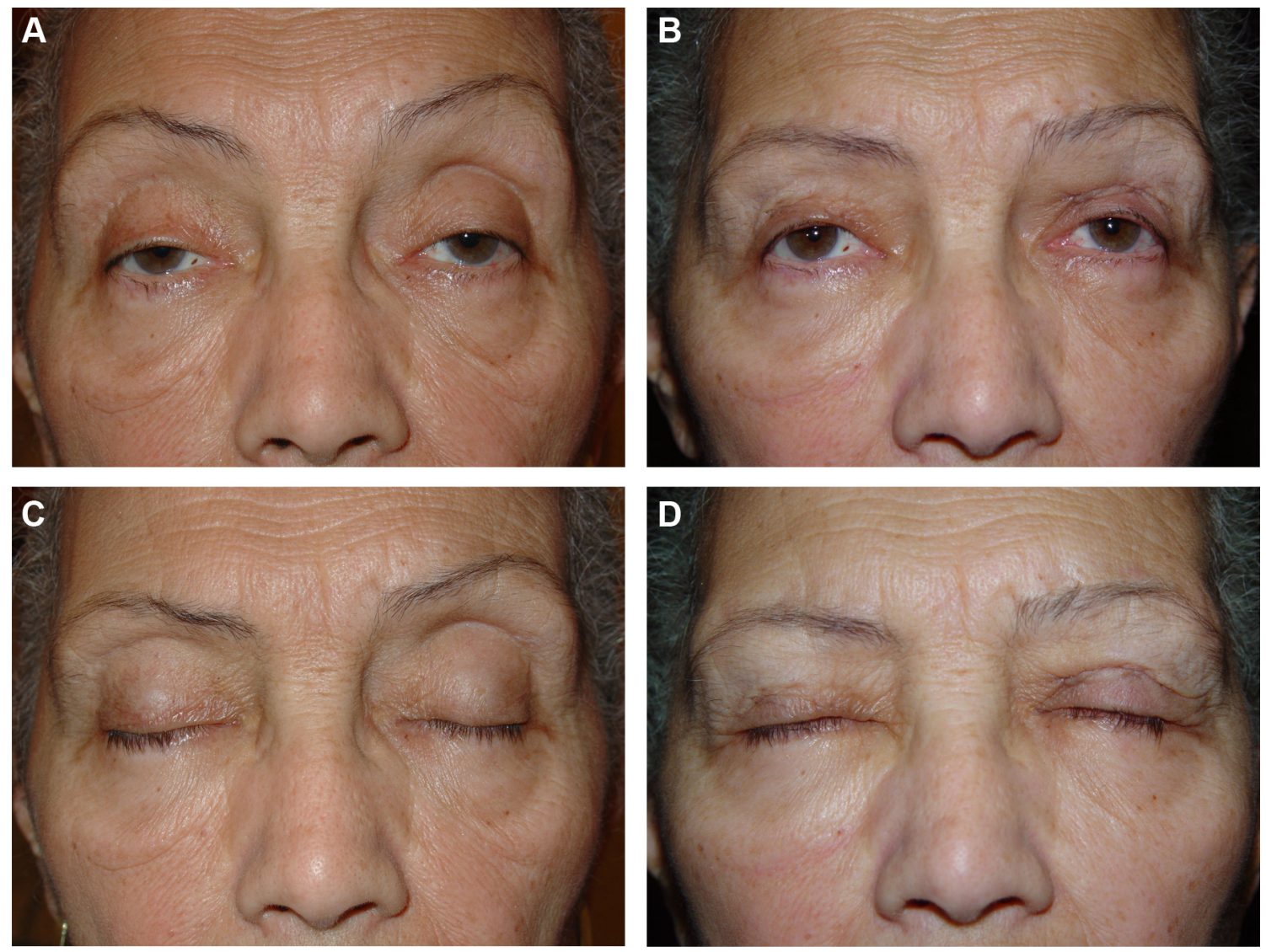

Figure 5 Preoperative and postoperative appearance of a 61-year-old female patient.

Notes: (A) Preoperative and (B) I-year postoperative photographs. (C) Perfect preoperative eyelid closure. (D) Postoperative photograph showing a mild lid-lag lagophthalmos.

Surgical correction should therefore be conservative and only performed when the visual axis is compromised. ${ }^{18}$

Kang et al consider that functional differences between oculopharyngeal muscular dystrophy and other myopathies may influence the choice of surgical technique. In myotonic dystrophy, orbicularis function is frequently affected, whereas in oculopharyngeal muscular dystrophy orbicularis function remains intact. The surgery in myopathic ptosis must be conservative because of the higher risk of postoperative corneal complications. However, in oculopharyngeal muscular dystrophy, the surgical procedure may not be so conservative if orbicularis function is normal and Bell's phenomenon is present. Kang et al have reported correcting ptosis using the levator resection technique in four patients with oculopharyngeal muscular dystrophy. ${ }^{19}$

Chronic exposure keratopathy related to correction of ptosis in patients with CPEO has been reported by several groups. ${ }^{20-22}$ Becerra et al described corneal complications after levator resection surgery that appeared in two patients with acquired myogenic eyelid ptosis and fair elevator function. ${ }^{21}$

An anterior approach elevator muscle advancement procedure was described in CPEO patients with more than
$4 \mathrm{~mm}$ of levator function, while a lid/brow suspension technique was used in patients with smaller levator function and relative sparing of the frontalis muscle. ${ }^{17}$ Wong et al indicated a lid/brow suspension procedure when the patient's levator muscle function was less than $8 \mathrm{~mm}$. They inserted autogenous fascia lata slings in three patients from a series including a total of 14 patients, with silastic slings used in the remaining eleven patients. ${ }^{18}$ Frontalis suspension and conjunctivomullerectomy have been reported in three patients with $\mathrm{KSS},{ }^{20}$ and a levator muscle advancement was performed on a 16-year-old patient with severe blepharoptosis and KSS. ${ }^{23}$

We chose a lid/brow elevation technique using autogenous fascia lata for all the seven patients described in this study because their levator muscle function was universally less than $5 \mathrm{~mm}$. Lid elevation was always moderate just to relieve the visual axis as confirmed by postoperative VFW and MRD measurements. All our patients developed a slight lower eye gaze lagophthalmos but retained a reasonable capacity for occlusion despite the conservative approach used. One patient developed postoperative exposure keratitis and conjunctivitis 
that evolved into a corneal ulcer and subsequent leukoma of the inferior cornea, but it did not affect the visual axis.

We believe that patients with acquired myogenic eyelid ptosis are at potential risk of developing postoperative surgical corneal exposure due to orbicularis oculi muscle atony and a poor Bell's phenomenon. Therefore, the decision regarding surgical correction should always be conservative, and is only indicated when the visual axis is compromised. We also believe that judicious use of an autogenous fascia lata lid/brow elevation procedure is a safe and efficient way of improving the visual acuity in CPEO patients with poor visual efficiency due to severe eyelid ptosis.

\section{Disclosure}

The authors have no conflicts of interest or financial ties to disclose in this work.

\section{References}

1. Kearns TP, Sayre GP. Retinitis pigmentosa, external ophthalmoplegia, and complete heart block: unusual syndrome with histologic study in one of two cases. Arch Ophthalmol. 1958;60:280-289.

2. Butler IJ, Gadoth N. Kearns-Sayre syndrome: a review of a multi system disorder of children and young adults. Arch Intern Med. 1976; 136:1290-1293.

3. Leveille AS, Newell FW. Autosomal dominant Kearns-Sayre syndrome. Ophthalmology. 1980;87:99-108.

4. Bernal JE, Winz O, Tamayo M. The Kearns-Sayre syndrome in three members of a consanguineous Colombian family. In: Vogel F, Sperling K, editors. Proceedings of the Seventh International Congress on Human Genetics. Berlin, Germany: Springer-Verlag; 1986.

5. Pavlakis SG, Rowland LP, DeVivo DC, et al. Mitochondrial myopathies and encephalomyopathies. In: Plum F, editor. Contemporary Neurology. Philadelphia, PA, USA: F.A. Davis Company; 1988.

6. DiMauro S, Moraes CT. Mitochondrial encephalomyopathies. Arch Neurol. 1993;50:1197-1208.

7. Kearns TP. External ophthalmoplegia, pigmentary degeneration of the retina and cardiomyopathy: a newly recognized syndrome. Trans Am Ophthlamol Soc. 1965;63:559-625.

8. Ascaso FI, Lopez-Gallardo E, Del Prado E, Ruiz-Pesini E, Montoya J. Macular lesion resembling adult-onset vitelliform macular dystrophy in Kearns-Sayre syndrome with multiple mtDNA deletions. Clin Experiment Ophthalmol. 2010;38:812-816.
9. Jager BV, Fred HL, Butler RB, Carnes WH. Occurrence of retinal pigmentation, ophthalmoplegia, ataxia, deafness and heart block: report of a case, with findings at autopsy. Am J Med. 1960;29:888-893.

10. Olson W, Engel WK, Walsh GO, Einaugler R. Oculocraniosomatic neuromuscular disease with 'ragged-red' fibers: histochemical and ultrastructural changes in limb muscles of a group of patients with idiopathic progressive external ophthalmoplegia. Arch Neurol. 1972;26:193-211.

11. Schmitz K, Lins H, Behrens-Baumann W. Bilateral spontaneous corneal perforation associated with complete external ophthalmoplegia in mitochondrial myopathy (Kearns-Sayre syndrome). Cornea. 2003;22:267-270.

12. Sebastiá R, Herzog Neto G, Fallico E, Lessa S, Solari HP, Ventura MP. A one-stage correction of the blepharophimosis syndrome using a standard combination of surgical techniques. Aesthetic Plast Surg. 2011;35:820-827.

13. Friedhofer H, Nigro MV, Filho AC, Ferreira MC. Correction of blepharophimosis with silicone implant suspensor. Plast Reconstr Surg. 2006; 17:1428-1434.

14. Taylor A, Strike PW, Tyers AG. Blepharophimosis-ptosisepicanthus inversus syndrome: objective analysis of surgical outcome in patients from a single unit. Clin Experiment Ophthalmol. 2007;35:262-269.

15. Wu SY, Ma L, Tsai YJ, Kuo JZ. One-stage correction for blepharophimosis syndrome. Eye (Lond). 2008;22:380-388.

16. Nakajima T, Yoshimura Y, Onishi K, Sakakibara A. One-stage repair of blepharophimosis. Plast Reconstr Surg. 1981;87:24-31.

17. Lane CM, Collin JR. Treatment of ptosis in chronic progressive external ophthalmoplegia. Br J Ophthalmol. 1987;71:290-294.

18. Wong VA, Beckingsale OS, Oley CA, et al. Management of myogenic ptosis. Ophthalmology. 2002;109:1023-1031.

19. Kang DH, Koo SH, Ahn DS, Park SH, Yoon ES. Correction of blepharoptosis in oculapharingeal muscular dystrophy. Ann Plast Surg. 2002;49:419-423.

20. Cesneková T, Jurecka T, Skorkovská K, et al. [Corneal ulceration complicating surgical correction of ptosis in patient with Kearns-Sayre syndrome - a case report]. Cesk Slov Oftalmol. 2011;67:133-135. Czech.

21. Becerra EM, Blanco G, Muiños Y, et al. [Tratamiento quirúrgico de ptosis palpebral miogénica adquirida]. Arch Soc Esp Oftalmol. 2005;80: 359-364. Spanish.

22. Daut PM, Steinemann TL, Westfall CT. Chronic exposure keratopathy complicating surgical correction of ptosis in patients with chronic progressive external ophthalmoplegia. Am J Ophthalmol. 2000; 130:519-521.

23. Papageorgiou G, Vlacos S, Tentis D. Blepharoptosis due to Kearns-Sayre syndrome. J Plast Reconstr Aesthet Surg. 2008;61: $573-574$.
Clinical Ophthalmology

\section{Publish your work in this journal}

Clinical Ophthalmology is an international, peer-reviewed journal covering all subspecialties within ophthalmology. Key topics include: Optometry; Visual science; Pharmacology and drug therapy in eye diseases; Basic Sciences; Primary and Secondary eye care; Patient Safety and Quality of Care Improvements. This journal is indexed on Submit your manuscript here: http://www.dovepress.com/clinical-ophthalmology-journal

\section{Dovepress}

PubMed Central and CAS, and is the official journal of The Society of Clinical Ophthalmology (SCO). The manuscript management system is completely online and includes a very quick and fair peer-review system, which is all easy to use. Visit http://www.dovepress.com/ testimonials.php to read real quotes from published authors. 